\title{
THE ANALYSIS OF DIGITAL MARKETING AMONG SMES IN
}

\section{CHAOZHOU CITY}

\author{
Caiyong Zhuang \\ Hanshan Normal University, Chaozhou 521000, Guangdong, Peoples R China \\ Shanwei Lin \\ Hanshan Normal University, Chaozhou 521000, Guangdong, Peoples R China
}

Fu Lin

Chaozhou Vocational Technical School, Peoples R China

\begin{abstract}
With the growing importance of digital marketing among companies, it is essential for the companies, especially the SMEs, to take a proactive approach in utilizing the digital marketing channels. The purpose of this essay is to investigate SMEs' digital marketing usage in Chaozhou and to provide recommendations for its future development. Factors which have negative impact on adopting digital marketing channels among SMEs in Chaozhou are identified based on the findings originated from the interviews and survey conducted among SMEs managers and owners respectively in Chaozhou, followed by the recommendations to minimize the impact of factors.
\end{abstract}

Keywords: Digital Marketing, Chaozhou, SMEs

JEL code: M310

\section{Introduction}

Digitization has become part of our daily life and it's changing the way in which consumers and businesses interact with each other. Nowadays, consumers spend more and more time online, they use online services for emailing, shopping, accessing social media apps (e.g. We chat/Weibo in China) and much more via various connected devices such as laptops, tablets and smart phones. Kaplan and Haenlein claimed that digitization has transformed consumer behavior significantly (See Kaplan \& Haenlein, 2010) and the importance of utilizing digital channels for brands cannot be ignored, as the sayings goes "If a company cannot be found in Google, it does not exist", this indicates that digital marketing is no longer an option but the imperative for the company if it wants to stay competitive and grow, and SMEs are no exception, however, it seems that SMEs didn't maximize the potential that digital channels could offer (See Inside small business, 2017). SMEs play a significant role within the world economy, particular in the developing countries where most formal jobs are generated by SMEs (See World Bank, 2015), thus, it could create practical benefits to SMEs by analyzing 
the SMEs' digital marketing and providing recommendations for its future development in the developing countries. The essay will introduce the city of Chaozhou and digital marketing (See The rising lab, 2017), followed by the analysis of digital marketing usage among SMEs in Chaozhou and recommendations for its future development.

\subsection{Introduction of Chaozhou and Digital Marketing}

Chaozhou city is located in the eastern part of Guangdong province with over 1,600 years' history, the city is a famous historical and cultural city in China and enjoy a high reputation home and abroad for industries such as tea, ceramic, evening dresses, wood engravings, embroidery and so on. Chaozhou has been awarded the status of "Chinese Porcelain City" and "Chinese Arts and Crafts City" (See Chaozhou Government, 2017).

While Chaozhou gains a high reputation in some industries, its GDP is ranked around the bottom within Guangdong Province, this is due to the following factors such as location, proportion of enterprise types and so on. Take the location for example, in Guangdong Province, the Pearl River Delta region is the center of Economic and Culture and Chaozhou is not part of it, which implies Chaozhou's development is in a disadvantage position when comparing with other cities within the region. Also, over $98 \%$ of 20,000 registered enterprises in Chaozhou are SMEs.

\subsection{Digital Marketing}

Digital marketing is a new approach to marketing and the concept of it is very broad. There are different ways to classified digital channels and this essay will use Heini's ways to classify the channels based on the perspective of which party dominates the communications (the company or the target audience) and whether communications is one-way or two-way (See Heini,Taiminen \& Heikki, 2015) (Table 1).

\begin{tabular}{|c|l|c|c|}
\hline & High Compary Control & & Lour compary Control \\
\hline \multirow{3}{*}{ One way } & Websi tes & & SEO \\
\cline { 2 - 4 } & Email-Newsletters & & SEA \\
\cline { 2 - 4 } & Online Advertising & & \\
\hline \multirow{2}{*}{ Two way } & Company's Blog & & Social Media \\
\hline
\end{tabular}

Table 1: Classification of digital marketing channels

One-way communication channels

Website, email can be considered as examples of one-way online channels with high company control. A website can offer the tool for anyone to access the information about the company at any time. Email, although is a two-way communication tool in its nature, it is often used as one-way communication tool for the company to send promotional emails and newsletter to build and maintain the relationships with the customers. Online advertising, which mainly showcasing promotional information to the online consumer, is also considered as one-way communication with high company control (See Wikipedia, 2017). In addition, both Search 
engine optimization (SEO) and Search engine advertising (SEA) are both regarded as one-way communication tools, with SEO helps the websites to get the top rank on the search engine result pages by optimizing for keywords, while SEA helps the websites to get the top rank in the search engine results pages by means of paid advertisement, such as Google AdWords or Baidu Tuiguan.

Two-way communication channels

Social media (Wechat,Weibo and Youku) could help the company to connect with consumers directly to promote brand awareness and improve reputation, and even drive straight sales-related outcomes in some cases. With the rapid development of Social Media, the power has shifted from marketers to customers within social media channel (See Hennig at al.,2010).

Unlike Website and Email marketing tool, the nature of social media requires company to use two-way communication to "talk" to the customers instead of one-way. Naturally, the company has less control with its brand in social media channels. The audiences do not expect commercial messages, but real information about the company and the brand when the company uses social media to reach them (See Fournier \& Avery, 2011).

Blogging is also a form of two-way communication social media channels where the company maintains a fairly high level of control as the content of blog is usually edited and the comments are monitored by the owners, it is said to be a good marketing and PR tool (See Ahuja \& Medury, 2010).

\section{Digital marketing and Chaozhou's SMEs}

Digital marketing can provide opportunities for SMEs to reach new and existing customer more efficiently, as well as to increase the companies' performance and competitiveness (See Shideler \& Badasyan, 2012). A recent study of 12 SMEs in the UK has also confirmed the positive relationship of utilizing digital marketing and improved performance (See Barnes et al., 2012). However, there are still some barriers to digital marketing usage among SMEs, especially in the less developed cities such as Chaozhou. In this essay, a semi structured interview technique and online survey were used to gather information of Chaozhou's SMEs' digital marketing activities, their chosen digital channels as well as the difficulties they experienced in using the digital marketing channels. We have conducted 12 1-2 hours interviews with various sizes and types of SMEs managers individually who were responsible for the marketing activity (including digital marketing) within their company; for the online survey, a total of 68 responses were received from owners, CEO or chairperson of SMEs.

According to the survey, nearly $40 \%$ of respondents considered they did badly or extremely badly in utilizing digital marketing, with just $10 \%$ of respondents marked their current digital marketing as very good or above. In terms of investment in digital marketing, it varies significantly, with over $35 \%$ of respondents defined that their digital marketing budget accounts for small proportion (4\%) of the total marketing budget, while $22 \%$ of the respondents invested over $35 \%$ of their marketing budget to digital marketing. 
Among the digital marketing channels, company's own website, leading B2C platforms (Such as Tmall, JD), email newsletter and social media are used most often. However, except the B2C platforms, most of these digital marketing tools are not actively used. For example, only $10 \%$ of respondents used company's website actively for marketing purpose, on the other hand, $32 \%$ of respondents didn't use the company's website at all. For utilizing SEO, with $10 \%$ and $50 \%$ of respondents use it actively and inactively respectively. For the social media, including the use of Wechat, Weibo and Youku, over 50\% of the companies did not use them at all and about $5 \%$ of companies used them actively. With respect to $\mathrm{B} 2 \mathrm{C}$ platforms, over $70 \%$ of the companies use them actively for e-commerce purpose primarily while acting as the main brands promoting and customer communication channel.

The findings from the interviews with 12 SMEs managers support the above statistics. Nearly $85 \%$ of the case companies run their business either in Tmall or JD (with some companies have both) platforms which regarded as the most important digital channel for marketing and communications purpose. In addition, website、 email newsletters s social media are ranked as the second third fourth most important digital channels for the company's marketing purpose, respectively according to the interviews results.

\section{Challenges of adopting digital marketing channels among SMEs in Chaozhou}

With consideration of Chaozhou, in addition with the survey and interviews conducted among the SMEs in Chaozhou, we have identified the following challenges which impact the wider use of digital marketing in SMEs in Chaozhou.

\subsection{Lack of company's resources}

Resources-related factors are classified as human resources, financial resources and technological resources (Karjaluoto \& Huhtamäki, 2010), and the lack of human resources and financial resources are the biggest barriers of digital marketing usage, this applied to SMEs and larger corporations (Järvinen et al., 2012). In addition, Sayre et al. (2012) suggested the employees' skill of utilizing the channel plays a significant influence of adopting or avoiding digital marketing in SMEs (Sayre et al., 2012).

According to the survey and interviews that we conducted, a significant percentage of SMEs' digital marketing has been described as unplanned or even disorganized, this is mainly due to the shortage of human resources, capital and expertise to utilize digital channels fully.

Digital marketing, unlike traditional marketing, requires "a dialogical communication style, continuous attention and participation as well as content are created" (Heini,Taiminen \& Heikki, 2015). Unfortunately, many of the SMEs in Chaozhou are in shortage of more inter-disciplinary talents to achieve this objective. On the other hand, finance factor can't be ignored, especially for SMEs. Digital marketing, at its best, has the advantages of low variable costs compared with the traditional marketing, the fixed costs may still have great impact to SMEs which have limited finance resources. SMEs, traditionally have difficulty in 
obtaining finance resources from the bank due to "insufficient assets and low capitalization, vulnerability to market fluctuations and high mortality rates"( Rita,2016), which inevitably create negative impact on the development of SMEs.

\subsection{Shortage of multi-channel digital marketing}

The Chinese leading B2C portals (Tmall and JD) offer excellent platforms for the SMEs to sell their products and services to customers, as well as offering the facilities for SMEs to engage with their customers. As the survey and interviews indicates, about $85 \%$ of "interviewed" SMEs in Chaozhou have their presence in Tmall or JD or both, and many agreed that B2C portals provide attractive digital marketing channel for SMEs. However, as the competition is growing, especially the recent introduction of Tmall Global and Taobao Global by Alibaba, some interviewed managers have expressed their concerns about their future development in this digital marketing channel. On the other hand, SMEs in Chaozhou seems not fully exploited the advantages of other digital marketing channels that available. For example, Social media has been claimed as an important channel in engaging customers and promoting brand awareness; blogging is also identified as a good relationship building tool for both marketing and PR (Ahuja \& Medury, 2010). SMEs in Chaozhou are recommended to change their digital marketing strategies to multi-channels if they want to stay competitive.

\section{Recommendation for digital marketing usage in Chaozhou's SMEs}

Based on the finding of the survey and interviews, most of the SMEs in Chaozhou agreed that the utilization of digital marketing can help to create positive impact of the development of SMEs online, however, there is no deny that many SMEs in Chaozhou didn't fully aware of the related benefits that digital marketing could bring to SMEs. The following recommendations for SMEs' digital marketing are provided below based on the case of Chaozhou.

\subsection{Solutions for SME's resources-shortage}

As the name "digital marketing" implies, multi-talented workforce are required to be competence with conducting digital marketing works effectively. Unfortunately, the shortage of digital marketing talents has been continues on globally, this has created impact on the Fortune 500 companies, not to mention the SMEs. To overcome this shortage, the SMEs in Chaozhou are advised to take the following approaches into consideration:

Offer digital marketing training programmers to the existing staff. This is one of the best ways to overcome the skill shortage, the training can be conducted internally or externally and this could also make the staff feel valued and thus, increases the retention rate of staff.

Build the partnership with local colleges or universities. The SMEs could benefit from the fresh graduates via the order form training programme with educational institutes, as the 
graduates are expected to be equipped with the core competence of being digital marketers after graduation. Moreover, the graduates will have more willingness and eagerness to learn new things than an experienced and knowledgeable person who is work-shy, this is claimed to be important especially in digital industry where technology are constantly changing (Sean, 2014).

Hire a professional digital marketing team or outsourcing. When the existing human resources cannot meet the demands of company's digital marketing job, hiring the professional or outsourcing can be the option depending on the company's circumstances, for example, outsourcing is considered as a good option for smaller startup SMEs whose budget is limited and outsourcing a digital marketing team could lower their budget significantly (Guest, 2017). On the other hand, when digital marketing work needs help in is a core function of the company, it is advised to hire a professional digital marketing team since the company will have greater control and the knowledge and skills are kept in house (Global Strategic, 2016).

Finance has been identified as one of the most important factors of determining the SMEs' future. Without sufficient financial support, it has been proved hard for SMEs to undertake productive investments such as to acquire or absorb new technologies to help SMEs stay competitive. To resolve the finance difficulty that SMEs face, the SMEs will need to take a proactive approach to secure the funding.

Traditionally, the funding sources for SMEs' owners are personal saving, friends, relatives and close associates, and normally, funding from these sources is not always adequate for SMEs' long-term development. In the meantime, it has proved difficult for the SMEs to borrow the money from the banks due to the inability of banks to access the reliable financial information of SMEs. To win the trust from banks, the SMEs are expected to reform themselves in the aspects of internal management, financial systems, training of the staff etc., in addition, the third-party rating agencies (Such as Alibaba enterprise integrity system) report can also be employed to demonstrate the SMEs' credibility. With transparent, reliable and comparable or even more financial information that banks require, the SMEs will have much better position to secure the funding from the banks.

The funding from the bank is a very important source for SMEs, but it is not the only option. In fact, there are growing numbers of funding sources for the SMEs to choose from, for example, with the increasing importance of SMEs in China, the Chinese government has offered a series of government funding schemes to support the development of SMEs, and SMEs in Chaozhou are advised to take advantages of them when appropriate; in addition, some SMEs, normally the high-tech SMEs, can consider seeking funding from venture capital companies or angel investors as at its best, they are not only providing you with the new funding but also new customers and people that could help to take your business to the next level. 


\subsection{Release the potential of other digital channels}

While a significant percentage of SMEs in Chaozhou utilize B2C platform as the primary means for selling and promoting the products, as well as communicating with the customers. In digital era, the customers, especially the potential customers, no longer make their decisions of purchase based on the advert on a single platform. Instead, they will search information about the brand and the products via the company's website, the social media, the review sites etc., to assist their decisions made. Therefore, SMEs in Chaozhou are suggested adopting a mix of platforms instead of relying heavily on B2C platform.

Based on result of the survey and interviews that we conducted among SMEs in Chaozhou, social media is a channel that SMEs in Chaozhou can easily ignore. According to Jones' finding, there is evidence that social media can help improving company's sales figure, brand image and awareness, as well as to enhance the communication process between companies and customers. In addition, social media can be adopted as a channel to gain detailed information about company's and competitors' products and brands, all the information collected from the channel can be used as important reference to support company's future marketing and product activities. Therefore, SMEs are encouraged to establish their presence on the leading social media platforms to gain the full potential of it (Jones, Borgman \& Ulusory, 2015).

\section{Conclusions}

This essay provides an overview of the usage and challenges related to digital marketing among SMEs in Chaozhou. Our study shows that digital marketing channels were not actively utilized by the participated SMEs for marketing purposes. On the basis of the penetration of the internet and social media usage in China, the result is not optimistic and further exploited of digital marketing channels by SMEs in Chaozhou is recommended.

SME's resources-shortage such as human resources and financial resources are regarding as the biggest barriers of digital marketing usage among the SMEs, and to enable SMEs to fully exploit the opportunities digital marketing channels can bring, SMEs are advised to take measures to minimize the barriers, for example, offering digital marketing training to the existing staff, working with local colleges or universities for customized graduates as well as hiring the management professionals or outsourcing the talents; regarding financial resources shortage, management reform is expected to meet the demanding requirements of banks for the loan, in the meantime, SMEs should actively seeking other funding sources such as government funds, venture capital or angel investors.

Although many of the SMEs in Chaozhou have their own websites and adopted B2C portals to sell the products as well as to communicate with the customers, the usage of more advanced digital channels such as social media tools is remained low, this is probably due to the SMEs' improper understanding of the social media tools, for example, the usage of social media tools can't help to generate sales or require very advanced IT skills which are SMEs' 
weaknesses. However, if SMEs want to enhance their ability for the future competition, deployed a website and utilized B2C portals are not enough, the companies should make sure that not only they can be found online, but also with positive brand images among other digital marketing channels.

The findings of this essay is based on one city with limited information generated from interviews and survey, therefore, the results cannot be fully applied to other settings or other cities. We would strongly encourage researchers to exploit SMEs' digital marketing channels in other cities in China and figure out whether location differences or other factors of SMEs have the impact on the companies' utilization of digital marketing channels.

\section{Acknowledgement}

This research is funded by Chaozhou philosophical social science program project: The proposal of City's image construction in Chaozhou and the strategy of the city of Chaozhou city construction strategy and promotion pathway study (Grant Number: 2015-A-10) and Youth project of Hanshan Normal University in 2015: Research on the construction of city's image in the city of Chaozhou (Grant Number: WQ201510). 


\section{References:}

Ahuja, V. and Medury, Y. (2010) "Corporate blogs as e-CRM tools - building consumer engagement through content management”, Journal of Database Marketing and Customer Strategy Management, Vol. 17 No. 2, pp. 91-105.

Ahuja, V. and Medury, Y. (2010) "Corporate blogs as e-CRM tools - building consumer engagement through content management”, Journal of Database Marketing and Customer Strategy Management, Vol. 17 No. 2, pp. 91-105.

Barnes, D., Clear, F., Harindranath, G., Dyerson, R., Harris, L. and Rea, A. (2012) "Web 2.0 and micro-businesses: an exploratory investigation", Journal of Small Business and Enterprise Development, Vol. 19 No. 4, pp. 687-711.

Chaozhou Government, "City introduction", Available: http://www.chaozhou.gov.cn/ssmp/38793.jhtml(1 August 2017).

Fournier, S. and Avery, J. (2011) “The uninvited brand”, Business Horizons, Vol. 54 No. 3, pp. 193-207.

Global Strategic (2016) "IN-HOUSE vs. OUTSOURCING", Available: https://www.globalstrategic.com/in-house-vs-outsourcing/(24 July 2017).

Guests, "Benefits of Outsourcing Marketing Activities", Available: https://www.ducttapemarketing.com/outsourcing-marketing/ (24 July 2017).

Heini Maarit Taiminen, Heikki Karjaluoto, (2015) "The usage of digital marketing channels in SMEs", Journal of Small Business and Enterprise Development, Vol. 22 Issue: 4, pp.633-651.

Hennig-Thurau, T., Malthouse, E. C., Friege, C., Gensler, S., Lobschat, L., Rangaswamy, A. and Skiera, B. (2010) "The impact of new media in consumer relationships", Journal of Service Research, Vol. 13 No. 3, pp. 311-330.

Inside small business (2017) "Small business yet to realize full potential of digital solutions", Available:https://insidesmallbusiness.com.au/sales-marketing/small-business-yet-to-realise-fu 1l-potential-of-digital-solutions(1 August 2017).

Järvinen, J., Töllinen, A., Karjaluoto, H. and Jayawardhena, C. (2012) "Digital and social media marketing usage in B2B industrial sector", Marketing Management Journal, Vol. 22 No. 2, pp. 102-117.

Jones, N., Borgman, R. and Ulusoy, E. (2015) "Impact of social media on small businesses", Journal of Small Business and Enterprise Development, Vol. 22, No. 4, pp. 611-632. 
Kaplan, A.M. and Haenlein, M. (2010), "Users of the world, unite! The challenges and opportunities of social media”, Business Horizons, Vol. 53 No. 1, pp. 59-68.

Karjaluoto, H. and Huhtamäki, M. (2010), "The role of electronic channels in micro-sized brick-and-mortar firms", Journal of Small Business and Entrepreneurship, Vol. 23 No. 1, pp. 17-38.

Rita Sarkodie Baffoe (2016), "Challenges faced by small and medium sized enterprises during recruitment and selection of employees within the madina metropolis in the la nkwantan/madina municipality of the greater accra region of Ghana", Global Journal of Human Resource Management, Vol.4, No.6, pp.7-33.

Sayre, K., Rastogi, V., Zwillenberg, P., Visser, J. and Sheerin, A. (2012), "Marketing capabilities for the digital age", Boston Consulting Group, Available: http://jcirera.files.wordpress.com/2012/02/bcg.pdf (2 July 2017).

Sean Little. (2014), "The advantages of hiring a fresh graduate", Available:https://www.firstjob.com/employer/blog/158/the-advantages-of-hiring-a-fresh-grad uate/(26 July 2017)

Shideler, D. and Badasyan, N. (2012), "Broadband impact on small business growth in Kentucky", Journal of Small Business and Enterprise Development, Vol. 19 No. 4, pp. 589-606.

The rising lab (2017), "What makes a good city", Available: http://www.therisinglab.com/interactive/reportfiles/2017report-2017rank.pdf (1 August 2017) Wikipedia, "Digital marketing", Available: https://en.wikipedia.org/wiki/Digital_marketing (24 July 2017)

World Bank (2015), "Small and Medium Enterprises (SMEs) Finance", Available: http://www.worldbank.org/en/topic/financialsector/brief/smes-finance (24 July 2017) 